\title{
Patient preferences for symptom-driven or regular preventer treatment in mild to moderate asthma: findings from the PRACTICAL study, a randomised clinical trial
}

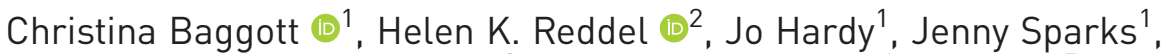 \\ Mark Holliday ${ }^{1}$, Andrew Corin ${ }^{3}$, Barney Montgomery ${ }^{4}$, Jim Reid ${ }^{5}$, \\ Davitt Sheahan ${ }^{6}$, Robert J. Hancox (1) ${ }^{7,8}$, Mark Weatherall9 , Richard Beasley (1) ${ }^{1,10}$ \\ and James Fingleton $\mathbb{1}^{1,10}$ on behalf of the PRACTICAL study team
}

@ERSpublications

In a clinical trial of patients with mild-moderate asthma comparing as-needed budesonide-formoterol with maintenance budesonide plus as-needed terbutaline, as-needed budesonide-formoterol was preferred by $90 \%$ of patients randomised to this treatment http://bit.ly/37DdUzB

Cite this article as: Baggott C, Reddel HK, Hardy J, et al. Patient preferences for symptom-driven or regular preventer treatment in mild to moderate asthma: findings from the PRACTICAL study, a randomised clinical trial. Eur Respir J 2020; 55: 1902073 [https://doi.org/10.1183/13993003.02073-2019].

ABSTRACT Symptom-driven low-dose inhaled corticosteroid-formoterol is safe and effective in mild asthma and has been recommended as one of the preferred treatment regimens at steps 1 and 2 in the 2019 update of the Global Initiative for Asthma. However, there are no data on patient preferences for this regimen.

A subgroup of participants in the PRACTICAL study (ACTRN12616000377437), a randomised controlled trial comparing symptom-driven budesonide-formoterol with maintenance budesonide plus as-needed terbutaline completed a survey on treatment preferences, satisfaction, beliefs and experience at their final study visit.

$306(75 \%)$ out of 407 eligible participants completed the survey. Regimen preference was strongly associated with randomised treatment, as were preferences for and beliefs about preventer inhaler use. Combination preventer and reliever as-needed therapy was preferred by 135 (90\%, 95\% CI 85.2-94.8\%) out of 150 who were randomised to as-needed budesonide-formoterol, and by 63 (40\%, 95\% CI 32.7 48.1\%) out of 156 who were randomised to maintenance budesonide. By contrast, twice-daily preventer inhaler with a reliever inhaler as required was preferred by 15 (10\%) out of 150 of those randomised to asneeded budesonide-formoterol and 93 (60\%) out of 156 of those randomised to maintenance budesonide. Satisfaction with all study inhalers was high. Of patients randomised to as-needed budesonide-formoterol $92 \%(n=138)$ were confident using it as a reliever at the end of the study.

Although most participants preferred the regimen to which they had been randomised, this association was much stronger for those randomised to budesonide-formoterol as needed, indicating that most patients preferred as-needed corticosteroid-formoterol therapy if they had experienced it.

This article has supplementary material available from erj.ersjournals.com

This trial is registered with the Australian New Zealand Clinical Trials Registry (www.anzctr.org.au) with identifier number ACTRN12616000377437; UTN: U1111-1174-2273. Data availability: de-identified individual participant preference data collected during the PRACTICAL trial will be shared beginning 2 years after article publication with no end date. These data will be available to researchers who provide a methodologically sound proposal for the purposes of achieving specific aims outlined in that proposal. Proposals should be directed to R. Beasley via email (richard. beasley@mrinz.ac.nz) and will be reviewed by the PRACTICAL study management committee. Requests to access data to undertake hypothesis-driven research will not be unreasonably withheld. To gain access, data requesters will need to sign a data access agreement and to confirm that data will only be used for the agreed purpose for which access was granted. 


\section{Introduction}

Treatment options in mild asthma have expanded, following results from four randomised controlled trials (RCTs) into the safety and efficacy of symptom-driven low-dose budesonide-formoterol [1-4]. The 2019 update of the Global Initiative for Asthma (GINA) strategy for asthma management and prevention endorsed symptom-driven low-dose inhaled corticosteroids (ICS) in combination with formoterol, a fast-onset long-acting $\beta_{2}$-agonist for mild asthma. GINA now recommends that, for adults and adolescents with mild asthma, as-needed ICS-formoterol is preferred to short-acting $\beta_{2}$ agonist (SABA) reliever therapy alone (step 1), and is an alternative to maintenance low-dose ICS plus as-needed SABA (step 2) [5, 6].

From a medical perspective, symptom-driven ICS-formoterol is an attractive regimen for mild asthma, as it has the potential to circumvent the problem of SABA overuse and ICS underuse during periods of asthma worsening [7, 8]. Despite having apparently mild asthma, patients are at risk of severe exacerbations [9], which are often associated with poor adherence to ICS [10]. There is evidence that patients prefer regimens that are less intrusive [11], prefer to increase their reliever medications over their preventer medications [12], have concerns about the necessity of using preventer inhalers regularly [13] and want to have control over how they use their asthma medications [14]. A potential advantage of symptom-driven ICS-formoterol is that it may align more closely with patients' preferences and current patterns of use in the real world. However, as it is a novel management strategy, there are no data as to whether a symptom-driven ICS-formoterol regimen is acceptable to patients, or of patients' experiences of using symptom-driven ICS-formoterol to control asthma.

The PRACTICAL study was an open label study of low dose as-needed budesonide-formoterol for symptom relief or twice-daily maintenance budesonide plus as-needed terbutaline for symptom relief [4]. Within this study a subgroup of participants completed a survey at their final study visit, exploring their preferences, beliefs, satisfaction, patterns of use and experience with respect to the study inhaler regimens.

\section{Methods \\ Description of the PRACTICAL study}

The methods and results for the PRACTICAL study are reported in detail elsewhere [4, 15]. The PRACTICAL study was a 52-week open-label parallel-group, multicentre, phase III RCT undertaken at sites across New Zealand (ACTRN 12616000377437). Adults aged 18-75 years with a self-reported doctor diagnosis of asthma who were taking either SABA alone or together with maintenance ICS, and so were eligible for step 2 treatment of the GINA 2014 strategy [16], were recruited. Participants were randomised to budesonide-formoterol Turbuhaler (Symbicort ${ }^{\mathrm{TM}}$ ) 200/6 $\mu \mathrm{g}$ (one inhalation for relief of symptoms as required) or budesonide Turbuhaler (Pulmicort ${ }^{\mathrm{TM}}$ ) $200 \mu \mathrm{g}$ (one inhalation twice a day) plus terbutaline (Bricanyl ${ }^{\mathrm{TM}}$ ) $250 \mu \mathrm{g}$ (two inhalations as required for relief of symptoms). Neither participants nor investigators were blinded to treatment allocations and no placebo inhalers were used. Both the survey and PRACTICAL study had ethical approval from the Northern B Health and Disability Ethics Committee, reference $15 / \mathrm{NTB} / 178$.

\section{Participants}

This was a substudy nested within the PRACTICAL study. Participants at six of the 15 sites in New Zealand who were due their final study visit on or after March 26, 2018 were eligible to complete the survey. Participants who had withdrawn from the study prior to this date, but would have otherwise been eligible were contacted and invited to complete the survey retrospectively.

\section{Survey design}

The survey design was informed by the study aims and review of the literature, which identified patterns of behaviour with respect to asthma management, poor adherence, beliefs about medicines and preferences for asthma medications as important themes to be explored. Where relevant, we incorporated existing questions [7, 17, 18]. The full survey is supplied in the supplementary material. During the survey, participants were asked their preferred choice of future inhaler regimen; this was a dichotomous choice

Affiliations: ${ }^{1}$ Medical Research Institute of New Zealand, Wellington, New Zealand. ${ }^{2}$ Woolcock Institute of Medical Research, University of Sydney, Sydney, Australia. ${ }^{3}$ Clinical Horizons, Tauranga, New Zealand. ${ }^{4}$ Optimal Clinical Trials Ltd, Auckland, New Zealand. ${ }^{5}$ RMC Research Ltd, Dunedin, New Zealand. ${ }^{6}$ Papamoa Pines Medical Centre, Tauranga, New Zealand. ${ }^{7}$ Waikato Hospital, Hamilton, New Zealand. ${ }^{8}$ University of Otago, Dunedin, New Zealand. ${ }^{9}$ University of Otago Wellington, Wellington, New Zealand. ${ }^{10}$ Capital and Coast District Health Board, Wellington, New Zealand.

Correspondence: Christina Baggott, Medical Research Institute of New Zealand, Wellington Regional Hospital, Newtown, Wellington, 6021, New Zealand. E-mail: Christina.baggott@mrinz.ac.nz 
between "a combined preventer and reliever inhaler taken as needed" or "a preventer inhaler taken twice a day every day, with a reliever inhaler taken as needed". The questions in the rest of the survey represented the following themes: preferences for preventer inhaler use; beliefs around use of preventer inhalers; satisfaction with the study inhalers; patterns of reliever inhaler use; and, for those randomised to as-needed budesonide-formoterol, their experience of this regimen. Responses were recorded using five-point Likert scales. The survey was piloted on 11 people with mild asthma to test ease of understanding, relevance of questions and cognitive burden. Cognitive debriefing techniques were used to enhance feedback on the survey. During pilot testing iterative changes were made to improve the understanding of the survey.

\section{Survey delivery}

The survey was undertaken at the final study visit, or if the participant had withdrawn before March 26, 2018 they were invited to return to undertake the survey. Prior to starting the survey all participants provided separate written informed consent and read an information sheet, explaining the terms "preventer", "reliever" and "combination", and incorporating the relevant part of the original participant information statement to describe the two inhaler regimens that were being investigated in the PRACTICAL study (supplementary figure S1). The survey data were collected and managed using REDCap electronic data capture tools hosted at the Medical Research Institute of New Zealand (Wellington, New Zealand) $[19,20]$. The participants self-completed the survey online in the same room as an investigator; if they had a query they were referred to the information sheet or asked to answer the question to the best of their ability.

\section{Outcomes}

The primary outcome was the proportion of participants stating a preference for each regimen in response to the question "which of the following asthma treatment plans would you prefer? A combined preventer and reliever inhaler taken as needed or a preventer inhaler taken twice a day every day, with a reliever inhaler taken as needed?"

Secondary outcomes included participants' preferences for and beliefs around preventer inhaler use, satisfaction with study inhalers, patterns of study reliever inhaler use and experience of using symptom-driven budesonide-formoterol.

\section{Statistical analysis}

Continuous variables are described by mean \pm SD or median (interquartile range), and categorical variables, including the primary outcome by frequencies and proportions expressed as a percentage. The association between regimen preference and randomised treatment was analysed by logistic regression and an interaction term tested if stated preference differed by ICS use prior to randomisation and study randomised treatment. Likert-scale secondary outcome variables were analysed by ordinal logistic regression to estimate the association with randomised treatment and an interaction term tested if response differed by ICS use prior to randomisation and study randomised treatment. For descriptive purposes agree/strongly agree responses were aggregated. No corrections were made for multiple analyses and the secondary analyses should be considered exploratory.

SAS version 9.4 (SAS Institute, Cary, NC, USA) was used for all analyses.

\section{Results}

407 participants were eligible to undertake the survey. Participant flow is shown in supplementary figure S2; 307 (75\%) out of 407 participants started the survey and 306 completed it. Participants who started the survey were older, had higher self-reported pre-study ICS adherence and were less likely to have withdrawn early than those who did not (table 1). Baseline characteristics of those who started the survey by randomised treatment are given in supplementary table S2. Similar proportions of participants from each randomisation arm completed the survey. Of those who started the survey, 20 (6.5\%) had withdrawn from the RCT before completion; these "early-withdrawers" represented $26 \%$ of the 76 participants who were withdrawn. Reasons for early withdrawal and for not undertaking the survey are given in supplementary figure S2.

\section{Primary outcome}

Most participants stated a preference for the treatment regimen to which they had been randomised. Of those randomised to budesonide-formoterol as needed, 135 (90\%, 95\% CI 85.2-94.8\%) out of 150 preferred combination preventer and reliever as needed and $15(10 \%)$ out of 150 preferred twice-daily preventer inhaler with a reliever inhaler as required. By contrast, of the 156 participants randomised to maintenance budesonide plus as-needed terbutaline, 63 (40\%, 95\% CI 32.7-48.1\%) preferred combination preventer and reliever as needed, and $93(60 \%)$ preferred twice-daily preventer inhaler with a reliever 
TABLE 1 Participant characteristics

Survey not started

100

Participants

Randomised treatment

Budesonide-formoterol

Maintenance budesonide

Baseline characteristics

Age years

Female

Ethnicity

Asian

New Zealand European

Māori

Other

Pacific

Smoking status

Current smokers

Ex-smokers

Never-smokers

Pack-years (among ever-smokers)

Age at diagnosis years

Mean \pm SD

Median (IQR)

Self-reported ICS use in the 12 weeks prior to randomisation

Self-reported ICS adherence

Self-reported ICS use ever

Self-reported frequency of SABA use in 4 weeks prior to randomisation

Mean \pm SD

Median (IQR)

Min-max

Participants with $\geqslant 1$ lifetime hospital admissions for asthma

Participants with $\geqslant 1$ severe exacerbation in the 12 months prior to study entry

GINA level of asthma symptom control at randomisation

Well controlled

Part controlled

Uncontrolled

\section{End-of-study characteristics ${ }^{+}$}

Final-visit $A C Q-5^{\S}$

Final-visit on treatment $\mathrm{FEV}_{1} \%$ predicted ${ }^{f}$

Final-visit $F_{\text {eNO }} \mathrm{ppb}$

Participants experiencing $\geqslant 1$ exacerbation or severe exacerbation during the study

Number of severe exacerbations during the study

0

1

2

Early withdrawal
$52(52)$

$48(48)$

$30.1 \pm 10.6$

$50(50)$

$10(10)$

67 (67)

$11(11)$

4 (4)

8 (8)

9 (9)

28 (28)

$63(63)$

$3.5 \pm 3.6$

$11.2 \pm 10.7$

7 (4-15.5)

$66(66)$

$40.5(32.8)(n=66)$

71 (71)

$4.0 \pm 4.0$

$3(1-5)$

$0-88$

18 (18)

14 (14)

$10(10)$

$50(50)$

40 (40)

$0.97 \pm 0.88(n=56)$

$88.3 \pm 15.9(n=54)$

$40.5(28-58)(n=54)$

15 (15)

$86(86)$

$12(12)$

2 (2)

$56(56)$
Survey started ${ }^{\#}$

307

151 (49)

$156(51)$

$45.9 \pm 16.2$

$172(56)$

$17(6)$

$247(81)$

$24(8)$

5 (2)

14 (5)

14 (5)

77 (26)

$214(70)$

$5.4 \pm 5.0$

$21.1 \pm 19.3$

14 (5-33)

$215(70)$

57.0 (35.9) $(n=215)$

$264(86)$

$4.0 \pm 5.2$

$2(1-5)$

$0-28$

40 (13)

28 (9)

76 (25)

151 (49)

$80(26)$

$0.78 \pm 0.72(n=307)$

$89.2 \pm 14.8(n=307)$

$23(15-40)(n=307)$

47 (15)

273 (89)

27 (9)

7 (2)

20 (7)

Data are presented as $n, n(\%)$, mean \pm SD or median (interquartile range (IQR)), unless otherwise stated. ICS: inhaled corticosteroid; SABA: short-acting $\beta_{2}$-agonist; GINA: Global Initiative for Asthma; ACQ-5: five-item Asthma Control Questionnaire; FEV ${ }_{1}$ : forced expiratory volume in 1 s: $F_{\mathrm{eNO}}$ : exhaled nitric oxide fraction. ${ }^{\#}: 307$ participants started the survey and 306 completed it; ${ }^{\text {" }}$ : patient-reported adherence to ICS in the 4 weeks prior to enrolment (\% prescribed dose); ${ }^{+}$: end-of-study characteristics were collected at the final study visit (either on completion of the study or on early withdrawal). The preferences survey was optional, so not all participants who attended a final study visit completed the survey. The higher rate of missing data in those who did not start the survey is due to participants who withdrew early without a final study visit or were lost to follow-up in this group. Participant flow is presented in supplementary figure S2; ${ }^{\S}$ : five questions that assess asthma symptoms in the previous week, each of which is scored on a seven-point scale that ranges from 0 (no impairment) to 6 (maximum impairment), and averaged, in which a 0.5 -unit change represents the minimal clinically important difference; ${ }^{f}$ : participants received no specific instruction to withhold use of their bronchodilator before measurement of $\mathrm{FEV}_{1}[21]$.

inhaler as required. Overall, a combined preventer and reliever inhaler taken as needed was the preferred regimen in 198 (65\%, 95\% CI 59.4-70.1\%) out of 306 participants and a preventer inhaler taken twice a day with a reliever inhaler as needed was the preferred regimen in 108 (35\%) out of 306. Participant characteristics by randomised treatment and preferred regimen are given in table 2 . Regimen preference in the 20 participants who withdrew from the study early and completed the survey are given in 
TABLE 2 Participant characteristics by randomised treatment and regimen preference

Randomised treatment

\begin{tabular}{|c|c|c|c|}
\hline \multicolumn{2}{|c|}{ Budesonide-formoterol as needed } & \multicolumn{2}{|c|}{$\begin{array}{l}\text { Maintenance budesonide plus as-needed } \\
\text { terbutaline }\end{array}$} \\
\hline \multicolumn{2}{|c|}{ Preferred treatment } & \multicolumn{2}{|c|}{ Preferred treatment } \\
\hline $\begin{array}{l}\text { Combined preventer } \\
\text { and reliever inhaler } \\
\text { taken as needed }\end{array}$ & $\begin{array}{l}\text { Preventer inhaler taken } \\
\text { twice a day with } \\
\text { a reliever inhaler } \\
\text { as needed }\end{array}$ & $\begin{array}{l}\text { Combined preventer } \\
\text { and reliever inhaler } \\
\text { taken as needed }\end{array}$ & $\begin{array}{l}\text { Preventer inhaler taken } \\
\text { twice a day with } \\
\text { a reliever inhaler } \\
\text { as needed }\end{array}$ \\
\hline
\end{tabular}

\section{Baseline characteristics}

Participants

Age years

Female

Age at diagnosis years

Mean \pm SD

Median (IQR)

Self-reported frequency of

SABA use in 4 weeks prior to

randomisation

Mean \pm SD

Median (IQR)

Self-reported ICS use in the

12 weeks prior to

randomisation

Self-reported ICS adherence ${ }^{\#}$

Self-reported ICS use ever

Participants with $\geqslant 1$ lifetime

hospital admissions for

asthma

Participants with $\geqslant 1$ severe

exacerbation in the

12 months prior to study

entry

Ever-smoker

Pack-years lamong

ever-smokers)

GINA level of asthma

symptom control at

randomisation

Well controlled

Part controlled

Uncontrolled

End-of-study characteristics

Final visit $A C Q-5^{\text {? }}$

Final visit $F_{\mathrm{eNO}} \mathrm{ppb}$

Final visit on treatment $\mathrm{FEV}_{1}$

$\%$ predicted $^{+}$

Participants who experienced

$\geqslant 1$ exacerbation or severe

exacerbation during the

study

Early withdrawal
135

$45.6 \pm 14.5$

78 (58)

$19.7 \pm 17.9$

$14(4-31.5)$

$3.9 \pm 5.1$

$2(1-5)$

$93(69)$

$53.1(36.7)$

$119(88)$

20 (15)

$12(9)$

42 (31)

$5.2 \pm 4.3$

$28(21)$

$68(50)$

39 (29)

$0.84 \pm 0.64$

$22(15-38.5)$

$89.5 \pm 14.8$

$16(12)$

$3(2)$

15

$44.1 \pm 23.2$

10 (67)

$23.9 \pm 26.9$

7 (4-42)

$4.4+5.9$

$2(0.5-5)$

11 (73)

67.5 (33.3)

14 (93)

2 (13)

1 (7)

$4(27)$

$5.8 \pm 7.8$

20 (32)

$6.5 \pm 5.9$

26 (28)

$5.2 \pm 5.2$

$4.2+4.9$

53.3 (38.2)

51 (81)

8 (13)

7 (11)

8 (9)

$80(86)$

10 (11)

$3.9 \pm 5.5$
$2(1-4)$

72 (77)

2.6 (33.7)

(1)

7 (47)

4 (27)

4 (27)

$1.00 \pm 0.76$

22 (15-47.5)

$92.6 \pm 17.6$

1 (7)

4 (27)

$12(19)$
$35(56)$
$16(25)$
$0.82 \pm 0.84$
$22(13-36.5)$
$89.7 \pm 14.4$

12 (19)

6 (10)
29 (31)

44 (47)

20 (22)

$0.62 \pm 0.73$

$23(15-40)$

$88.0 \pm 14.9$

18 (19)

7(8)

Data are presented as $\mathrm{n}$, mean \pm SD, $\mathrm{n}(\%)$ or median (interquartile range (IQR)), unless otherwise stated. SABA: short-acting $\beta_{2}$-agonist; ICS: inhaled corticosteroid; GINA: Global Initiative for Asthma; ACQ-5: five-item Asthma Control Questionnaire; $F_{\text {eNo: }}$ exhaled nitric oxide fraction; $\mathrm{FEV}_{1}$ : forced expiratory volume in $1 \mathrm{~s} .{ }^{*}$ : patient-reported adherence to ICS in the 4 weeks prior to enrolment (\% prescribed dose); ${ }^{\text {?: }}$ five questions that assess asthma symptoms in the previous week, each of which is scored on a seven-point scale that ranges from 0 (no impairment) to 6 (maximum impairment), and averaged, in which a 0.5-unit change represents the minimal clinically important difference; ${ }^{+}$: participants received no specific instruction to withhold use of their bronchodilator before measurement of FEV 1 [21]. 
TABLE 3 Regimen preference

\begin{tabular}{l} 
Pubjects \\
\cline { 2 - 3 }
\end{tabular}

supplementary table S3; the as-needed combination regimen was preferred by three (43\%) out of seven early-withdrawers randomised to as-needed budesonide-formoterol.

The odds ratio for association between randomised treatment and preference for a combined preventer and reliever inhaler was 13.3 (95\% CI 7.1-24.7; p<0.001) (table 3). The odds ratio after adjustment for whether the participant was taking maintenance ICS or not prior to randomisation was 13.6 (95\% CI $7.3-25.5 ; \mathrm{p}<0.001)$, suggesting that ICS use prior to randomisation did not change the association between randomised treatment and regimen preference.

TABLE 4 Preferences around preventer inhaler use

\begin{tabular}{|c|c|c|c|c|c|c|c|c|}
\hline & \multicolumn{6}{|c|}{ Randomised treatment } & \multirow[t]{2}{*}{ OR $(95 \% \mathrm{CI})^{\#}$} & \multirow[t]{2}{*}{ p-value } \\
\hline & \multicolumn{3}{|c|}{$\begin{array}{c}\text { Budesonide-formoterol } \\
\text { Preferred treatment }\end{array}$} & \multicolumn{3}{|c|}{$\begin{array}{c}\text { Maintenance budesonide } \\
\text { Preferred treatment }\end{array}$} & & \\
\hline Participants & 135 & 15 & 151 & 63 & 93 & 156 & & \\
\hline \multicolumn{9}{|l|}{$\begin{array}{l}\text { Participants who agree or strongly agree } \\
\text { with the following statement }\end{array}$} \\
\hline $\begin{array}{l}\text { I would prefer to take a preventer inhaler } \\
\text { every day to try and avoid as many } \\
\text { symptoms as possible }{ }^{+}[7]\end{array}$ & $51(38)$ & $13(87)$ & $64(42)$ & $27(43)$ & $80(86)$ & 107 (69) & $3.01(1.96-4.60)$ & $<0.001$ \\
\hline $\begin{array}{l}\text { I would prefer to adjust the amount of my } \\
\text { preventer inhaler to the changes in my } \\
\text { asthma taking less when feeling well } \\
\text { and more when feeling worse [7] }\end{array}$ & $101(75)$ & $4(27)$ & $106(70)$ & $41(65)$ & $31(33)$ & $72(46)$ & $2.62(1.71-4.0)$ & $<0.001$ \\
\hline \multicolumn{9}{|c|}{$\begin{array}{l}\text { Data are presented as } \mathrm{n} \text { or } \mathrm{n}(\%) \text {, unless otherwise stated. }{ }^{\#}: \mathrm{OR}>1 \text { indicates that survey respondents were more likely to agree with the } \\
\text { statement if randomised to as-needed budesonide-formoterol than if randomised to maintenance budesonide plus as-needed terbutaline; } \\
\eta_{:} \text {: one participant randomised to as needed budesonide-formoterol did not complete the survey. If they agreed/strongly agreed with a } \\
\text { statement then the sum of the as-needed preference and maintenance preference columns would be one less than the overall value; } \\
{ }^{+} \text {: direction of response was in the opposite direction to all other questions; this was reversed for analysis. }\end{array}$} \\
\hline
\end{tabular}




\begin{tabular}{|c|c|c|c|c|c|c|c|c|}
\hline & \multicolumn{6}{|c|}{ Randomised treatment } & \multirow[t]{3}{*}{ OR $(95 \% \mathrm{CI})^{\#}$} & \multirow[t]{3}{*}{ p-value } \\
\hline & \multirow{2}{*}{\multicolumn{3}{|c|}{$\begin{array}{c}\text { Budesonide-formoterol" }^{\text {" }} \\
\text { Preferred treatment }\end{array}$}} & \multirow{2}{*}{\multicolumn{3}{|c|}{$\begin{array}{c}\text { Maintenance budesonide } \\
\text { Preferred treatment }\end{array}$}} & & \\
\hline & & & & & & & & \\
\hline Participants & 135 & 15 & 151 & 63 & 93 & 156 & & \\
\hline \multicolumn{9}{|l|}{$\begin{array}{l}\text { Participants who agree or strongly agree } \\
\text { with the following statement }\end{array}$} \\
\hline $\begin{array}{l}\text { I consider it normal for me to get } \\
\text { symptoms of asthma }\end{array}$ & 97 (72) & $10(67)$ & $107(71)$ & $43(68)$ & $56(60)$ & $99(63)$ & $1.59(1.03-2.48)$ & 0.039 \\
\hline $\begin{array}{l}\text { When I feel well, I believe there is no } \\
\text { need to take a preventer inhaler every } \\
\text { day [7] }\end{array}$ & $90(67)$ & $4(27)$ & $95(63)$ & $32(51)$ & $18(19)$ & 50 (32) & $3.94(2.57-6.04)$ & $<0.001$ \\
\hline $\begin{array}{l}\text { I am concerned about taking too } \\
\text { much medication when I am well [7] }\end{array}$ & $69(51)$ & $3(20)$ & 73 (48) & $27(43)$ & $23(25)$ & 50 (32) & $1.85(1.23-2.78)$ & 0.003 \\
\hline \multicolumn{9}{|c|}{$\begin{array}{l}\text { Data are presented as } \mathrm{n} \text { or } \mathrm{n}(\%), \text { unless otherwise stated. }{ }^{\#}: \mathrm{OR}>1 \text { indicates that survey respondents were more likely to agree with the } \\
\text { statement if randomised to as-needed budesonide-formoterol than if randomised to maintenance budesonide; }{ }^{\text {n }} \text { : one participant randomised to } \\
\text { as-needed budesonide-formoterol did not complete the survey. If they agreed/strongly agreed with a statement then the sum of the as-needed } \\
\text { preference and maintenance preference columns would be one less than the overall value. }\end{array}$} \\
\hline
\end{tabular}

\section{Secondary outcomes}

Numbers and proportions of participants who agreed/strongly agreed (tables 4, 5 and 6) or who were satisfied/very satisfied (table 7) are summarised by randomised treatment and regimen preference.

\section{Preferences around preventer inhaler type and use}

Participants randomised to as-needed therapy were more likely to prefer not to take an inhaler every day, express a preference for being able to adjust dosing, and for all asthma medications to be combined into a single inhaler (table 4). Again, there was strong evidence of variation in response by randomisation arm, and these effects were not modified by ICS use prior to randomisation. The proportions of participants who agreed/strongly agreed to these questions were similar for participants who had expressed a preference for as-needed treatment between both randomised treatment arms.

\section{Beliefs around asthma and preventer inhaler use}

Participants randomised to budesonide-formoterol as needed were more likely to believe that a daily preventer was not necessary when they were feeling well, to have concerns about taking too much medication when they were feeling well, to consider it normal to get asthma symptoms and to have confidence in being able to intervene when asthma symptoms were worsening. There was no evidence of effect modification from use of ICS prior to randomisation. While more participants randomised to budesonide-formoterol as needed were willing to accept more asthma symptoms to avoid taking a daily preventer, numbers expressing agreement with this statement were low.

\section{Patterns of reliever inhaler use during the study}

For this set of statements there was weak or no association with randomised treatment. Most participants agreed they always carried their reliever inhaler with them and took their reliever inhaler as soon as they got mild symptoms. However, in both randomised groups approximately one-third waited until asthma was having an impact on what they were doing and almost $20 \%$ tried to avoid taking their reliever inhalers as much as possible. Approximately $30 \%$ admitted difficulty in recognising asthma symptoms. Responses to questions regarding timing of reliever inhaler use and numbers of participants who experienced an exacerbation are given in supplementary table S4. 
TABLE 6 Patterns of reliever use during the study

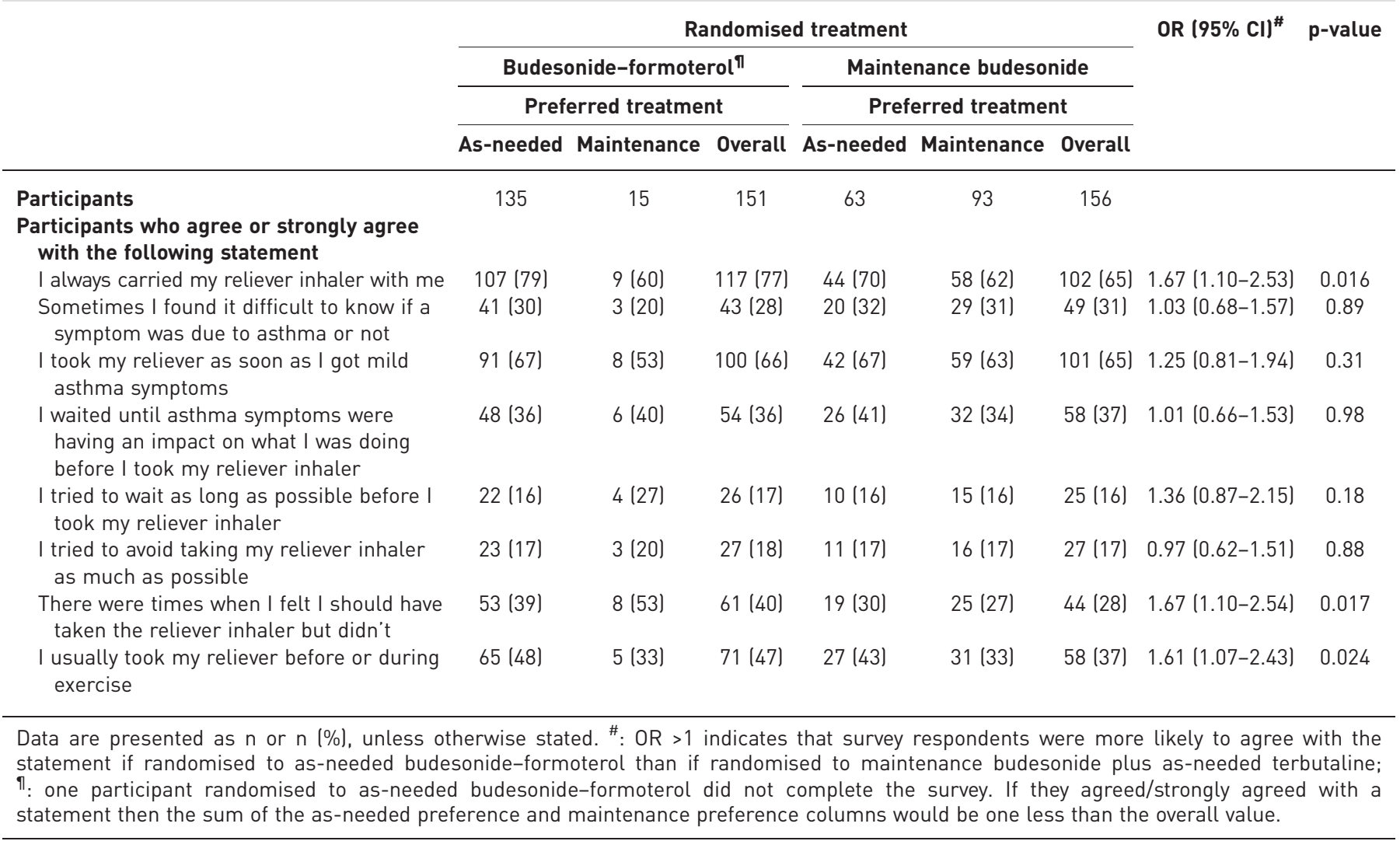

Satisfaction with study inhalers

Satisfaction with each study inhaler in all three domains (inhaler effectiveness, frequency of use and speed of action (reliever inhaler only)) was high. For each of the three domains, participants were more likely to be satisfied/very satisfied if they had been randomised to as-needed budesonide-formoterol. There was no evidence of effect modification from use of ICS prior to randomisation.

Experience of using budesonide-formoterol as symptom-driven preventer and reliever

Among participants randomised to as-needed budesonide-formoterol, 32 (21\%) out of 151 agreed/strongly agreed that they would have preferred to take a regular preventer inhaler to stop them getting asthma symptoms and $102(68 \%)$ out of 151 disagreed/strongly disagreed (table 8). More than one-third (55 (37\%) out of 150) agreed/strongly agreed that they were apprehensive about not taking their usual reliever inhaler any more. 111 (74\%) out of 150 reported that they had felt confident in using budesonideformoterol as a reliever inhaler at the start of the study and 138 (92\%) out of 150 reported that they felt confident with using budesonide-formoterol as reliever inhaler by the end of the study. Approximately one-third felt that the onset of budesonide-formoterol was faster than their previous reliever inhalers, one-third were uncertain and one-third felt that onset was slower than their previous reliever. In all, 66 (44\%) out of 150 felt that the duration of relief from budesonide-formoterol was longer than their previous reliever inhalers.

\section{Discussion}

This study has shown that the regimen that participants preferred and their response to questions on preferences for and beliefs around preventer inhalers were strongly associated with their randomised treatment. Most participants preferred their randomised treatment; however, a higher proportion of participants randomised to as-needed budesonide-formoterol than maintenance budesonide preferred their randomised treatment ( $90 \%$ versus $60 \%$ ), and use of ICS prior to randomisation did not affect preference. This suggests that patients are likely to prefer to use budesonide-formoterol as needed if they have experienced this regimen. Although most patients randomised to maintenance budesonide preferred 
TABLE 7 Satisfaction with study inhalers

\begin{tabular}{|c|c|c|c|c|c|}
\hline Budesonide-formoterol ${ }^{\#}$ inhaler & Terbutaline inhaler" & Budesonide inhaler & $\begin{array}{l}\text { Budesonide-fo } \\
\text { versus terbc }\end{array}$ & $\begin{array}{l}\text { moterol } \\
\text { aline }\end{array}$ & $\begin{array}{l}\text { Budesonide-formoterol } \\
\text { versus budesonide }\end{array}$ \\
\hline Preferred treatment & Preferred treatment & Preferred treatment & OR $(95 \% \mathrm{CI})^{+}$ & $\overline{p \text {-value }}$ & OR $\left(95 \% \mathrm{Cl}^{+} \quad \mathrm{p}\right.$-value \\
\hline
\end{tabular}

$\overline{\text { As-needed Maintenance Overall As-needed Maintenance Overall }} \overline{\text { As-needed Maintenance Overall }}$

\begin{tabular}{|c|c|c|c|c|c|c|c|c|c|c|c|c|c|}
\hline $\begin{array}{l}\text { Participants } \\
\text { Participants who were } \\
\text { satisfied or very } \\
\text { satisfied with the } \\
\text { following domains }\end{array}$ & 135 & 15 & 151 & 59 & 88 & 147 & 63 & 93 & 156 & & & & \\
\hline $\begin{array}{l}\text { Inhaler effectiveness } \\
\text { [18] }\end{array}$ & $129(96)$ & $10(67)$ & 140 (93) & $51(86)$ & $76(86)$ & $127(86)$ & $51(81)$ & $84(90)$ & 135 (87) & $2.74(1.74-4.29)$ & $<0.001$ & $2.37(1.53-3.68)$ & $<0.001$ \\
\hline $\begin{array}{l}\text { Frequency of inhaler } \\
\text { use [18] }\end{array}$ & 125 (93) & $8(53)$ & 134 (89) & $48(81)$ & $76(86)$ & $124(84)$ & $41(65)$ & 81 (87) & $122(78)$ & $1.90(1.21-2.97)$ & 0.005 & $2.26(1.46-3.51)$ & $<0.001$ \\
\hline $\begin{array}{l}\text { Reliever inhaler speed } \\
\text { of action }[18]^{\S}\end{array}$ & 118 (87) & $10(67)$ & $129(85)$ & $46(78)$ & $69(78)$ & $115(78)$ & & & & $1.56(1.01-2.41)$ & 0.044 & & \\
\hline
\end{tabular}

Data are presented as $\mathrm{n}$ or $\mathrm{n}(\%)$, unless otherwise stated. ${ }^{\#}$ : one participant randomised to as-needed budesonide-formoterol did not complete the survey. If they agreed/strongly agreed with a statement then the sum of the as-needed preference and maintenance preference columns would be one less than the overall value; ${ }^{\text {?: }}$ participants randomised to maintenance budesonide only saw questions on the terbutaline inhaler if they answered yes to using the inhaler during the study. Nine patients answered no; ${ }^{+}$: OR $>1$ indicates that survey respondents were more likely to agree with the statement if randomised to as-needed budesonide-formoterol than if randomised to maintenance budesonide; ${ }^{\S}$ : question only asked regarding budesonide-formoterol and terbutaline inhalers. 


\begin{tabular}{|c|c|}
\hline $\begin{array}{l}\text { I would have preferred to take a regular preventer inhaler to stop me getting asthma } \\
\text { symptoms }\end{array}$ & 151 \\
\hline Agree/strongly agree & $32(21)$ \\
\hline Uncertain & $17(11)$ \\
\hline Disagree/strongly disagree & 102 (68) \\
\hline I was apprehensive about not taking the reliever inhaler I was on before the study any more & 150 \\
\hline Agree/strongly agree & 55 (37) \\
\hline Uncertain & 20 (13) \\
\hline Disagree/strongly disagree & $75(50)$ \\
\hline Confidence in using budesonide-formoterol as a reliever inhaler at the start of the study & 150 \\
\hline Confident/very confident & $111(74)$ \\
\hline Uncertain & $28(19)$ \\
\hline Unconfident/very unconfident & $11(7)$ \\
\hline Confidence in using budesonide-formoterol as a reliever inhaler at the end of the study & 150 \\
\hline Confident/very confident & 138 (92) \\
\hline Uncertain & $5(3)$ \\
\hline Unconfident/very unconfident & $7(5)$ \\
\hline \multicolumn{2}{|l|}{$\begin{array}{l}\text { Compared to the reliever inhaler I was on before the study, I felt that when I took the } \\
\text { budesonide-formoterol inhaler, it worked }\end{array}$} \\
\hline A bit/a lot faster & 58 (39) \\
\hline About the same & $43(29)$ \\
\hline A bit/a lot slower & 49 (33) \\
\hline \multicolumn{2}{|l|}{$\begin{array}{l}\text { Compared to the reliever inhaler I was on before the study, I felt the length of time the } \\
\text { budesonide-formoterol inhaler worked for after I took a puff was }\end{array}$} \\
\hline A bit/a lot longer & $66(44)$ \\
\hline About the same & $60(40)$ \\
\hline A bit/a lot shorter & $24(16)$ \\
\hline
\end{tabular}

Data are presented as $\mathrm{n}$ or $\mathrm{n}(\%)$.

this treatment, patients may have been better able to make an informed choice after experiencing both regimens, and the regimen participants preferred may have reflected their satisfaction with their randomised treatment. Overall, our findings are consistent with evidence from other studies that show patients want quick symptom relief [22] and a flexible, easy-to-use asthma regimen over which they are in control $[13,14,23]$.

While most participants were satisfied with their study inhalers, participants randomised to the budesonide-formoterol inhaler reported higher degrees of satisfaction in all three domains investigated (inhaler effectiveness, frequency of use and speed of onset of the reliever inhaler) than those randomised to maintenance budesonide plus as-needed terbutaline.

This study complements findings from the SYGMA 1 and 2, Novel START and PRACTICAL studies [1-4] that symptom-driven budesonide-formoterol is a safe and effective alternative in mild to moderate asthma and suggests that the new GINA recommendation for symptom-driven ICS-formoterol at steps 1 and 2 [5] may be preferred by many patients over the alternative, maintenance ICS with a separate as-needed SABA reliever.

Most participants randomised to symptom-driven budesonide-formoterol rated their experiences of using this regimen favourably. While some participants reported they had been apprehensive about switching reliever, nearly all participants (92\%) said that they were confident in using budesonide-formoterol as a reliever by the end of the study. Hence, if a patient expresses reservations about this regimen, it may be worth suggesting that they try it for a period of time, as after a 12-month trial of the budesonideformoterol reliever therapy $90 \%$ of patients expressed a preference for this regimen.

It might be assumed that in order for budesonide-formoterol reliever therapy to be safe and effective, patients would need to take the inhaler in response to symptoms and not delay or avoid using it. We found that some patients admitted having difficulty recognising if a symptom was due to asthma or avoided or delayed taking their reliever inhalers. It is reassuring that they were in the minority with similar numbers in both treatment arms and that this pattern of response was not linked with a higher exacerbation rate (supplementary table S4). However, identification of symptoms and appropriate use of 
reliever inhalers should be considered when starting a patient on either therapeutic regimen, and they should be provided with education about when to use inhalers.

We pre-specified that we would examine the effect of ICS use prior to randomisation on preferences as we considered this was the characteristic most likely to have an effect. In fact, ICS use prior to randomisation did not affect response to any of the questions in the survey. We opted not to test interaction with other covariates due to risk of Type 1 error inflation. Because the overwhelming majority (90\%) of participants who were randomised to as-needed budesonide-formoterol preferred this treatment, randomised treatment was likely to dominate other characteristics. However, the participants in both treatment groups who did not prefer their randomised treatment are of interest. Review of their characteristics (table 2) suggests that they had worse asthma symptom control at the end of the study than those who preferred their randomised treatment. There were too few asthma exacerbations to assess the effect of experiencing an exacerbation during the study on regimen preference. It may be that regimen preference may be related to the individual's experience of using that regimen, particularly for those randomised to maintenance budesonide; in addition, health beliefs or factors specific to the individual may have an influence.

While we have shown that, among adult RCT participants with mild asthma, symptom-driven preventer reliever therapy was preferred to twice-daily preventer therapy with a reliever as required, we did not compare this with other regimens such as once-daily preventer therapy plus as-needed SABA or single maintenance and reliever therapy (SMART). We did not ask participants their preferred regimen at the start of the trial, so we cannot comment if their preferences changed. Participants randomised to maintenance budesonide did not have the opportunity to experience both regimens, whereas $88 \%$ of those randomised to budesonide-formoterol as needed had used maintenance ICS during their lifetime. Therefore, the preferred treatment, particularly of those randomised to maintenance budesonide, may reflect their satisfaction with their current regimen rather than a preference for maintenance treatment over as-needed treatment.

We asked participants to answer some questions on reliever and preventer inhaler use to reflect what they did or felt during the study, so the results for these questions will be vulnerable to recall bias. The key question about preferred regimen was asked after the participant had answered multiple questions about their beliefs, attitudes and experiences about asthma and treatment, so reflection on these issues may have influenced regimen preference. In addition, mood or prior expectation of undertaking the survey may have influenced response. As the survey was completed in the same room as an investigator, it is possible that they may also be affected by social desirability bias. To limit cognitive burden, we did not include any consistency-check questions. We opted not to exclude any questions for central tendency of response (where the middle option is chosen above all others) or straight lining (where the same option is repeatedly chosen), therefore we did not undertake any checks for these. Secondary end-points were not adjusted for multiplicity of analyses and should not be used to infer definitive outcomes.

Another limitation of the current study is that 100 eligible participants did not complete the survey. Comparison of their baseline demographics suggests that they may have been different from those who did. Participants who withdraw early from an RCT are more likely to have been nonresponders [24], and, as suggested by the treatment preferred by the small proportion of withdrawers who completed the survey (supplementary table S4), it is possible that the responses of other early-withdrawers could have been quite different from those that did complete the survey. This may affect the representativeness of our results; however, there was a similar noncompletion rate between the two treatment arms. In addition, the preferences of patients with mild asthma in the general population may be different from those who are willing to take part in an RCT for a year.

The strengths of this study are that it was investigator conceived, designed and implemented. It was independently funded with no involvement of pharmaceutical industry at any point. It was nested within the context of a RCT and is the first study to report on patient preference for and experiences of using as-needed budesonide-formoterol in mild asthma. The survey was implemented before the results of the SYGMA 1 and 2 studies [1,2] and the Novel START study [3] had been published. Therefore, we feel it is unlikely that participants would have been influenced by the results of these studies.

Our study highlights how investigation of patient preferences can be incorporated into RCTs. This may help us to understand the differences between effectiveness and efficacy seen when a treatment moves from a RCT into clinical practice [25], in which factors such as patient preferences and experience of a treatment are likely to play a role. Information on how different attributes of treatment regimens influence patient preferences, which can be determined from conjoint analysis methods such as discrete choice experiments, would provide additional understanding. Deeper understanding of patient preferences will be obtained from qualitative interviews. As ICS-formoterol as needed is incorporated into clinical practice, 
patient preferences for and experiences of using this regimen should be examined to determine if they are congruent with the patterns observed in this population of patients completing this RCT.

In conclusion, participants' future preference for inhaler regimen was strongly influenced by their randomised treatment; particularly if they had been randomised to budesonide-formoterol as needed, with $90 \%$ preferring this regimen to maintenance budesonide plus as-needed reliever. This suggests that in clinical practice, decision-making by a clinician and a patient about treatment of mild asthma could include the option of a trial of as-needed ICS-formoterol.

Acknowledgements: We thank the participants for their time and involvement, and the PRACTICAL study team (listed in the supplementary material).

Conflict of interest: C. Baggott reports grants from Health Research Council of New Zealand, during the conduct of the study; personal fees for meeting attendance from AstraZeneca and Novartis, outside the submitted work. H.K. Reddel reports grants from Health Research Council of New Zealand, during the conduct of the study; grants and personal fees for consultancy, advisory board and data monitoring committee work, and educational activities from AstraZeneca, grants, personal fees for consultancy, advisory board and data monitoring committee work, and educational activities and non-financial support (study medication) from GlaxoSmithKline, personal fees for data monitoring committee work from Merck, grants and personal fees for advisory board and data monitoring committee work, and educational activities from Novartis, personal fees for educational activities from Teva and Mundipharma, personal fees for educational activities and advisory board work from Boehringer Ingelheim, outside the submitted work; and is Chair of the GINA Scientific Committee. J. Hardy reports grants from Health Research Council of New Zealand, during the conduct of the study; personal fees for meeting attendance from AstraZeneca, outside the submitted work. J. Sparks reports grants from Health Research Council of New Zealand, during the conduct of the study. M. Holliday reports grants from Health Research Council of New Zealand, during the conduct of the study. A. Corin reports grants from Health Research Council of New Zealand, during the conduct of the study; grants and personal fees for meeting attendance from AstraZeneca, personal fees for lectures and meeting attendance from GlaxoSmithKline, grants from resTORbio, Regeneron, Esperion, Connect Biopharma and Luitpold, and is a committee member for PHARMAC, outside the submitted work. B. Montgomery reports grants from Health Research Council of New Zealand, during the conduct of the study. J. Reid reports grants from Health Research Council of New Zealand, during the conduct of the study. D. Sheahan reports grants from Health Research Council of New Zealand, during the conduct of the study. R.J Hancox reports grants from Health Research Council of New Zealand, during the conduct of the study; grants and reimbursement of travel expenses from AstraZeneca, reimbursement of travel expenses from Boehringer Ingelheim, personal fees for lectures from Menarini, outside the submitted work. M. Weatherall reports grants from Health Research Council of New Zealand, during the conduct of the study. R. Beasley reports grants from Health Research Council of New Zealand, during the conduct of the study; grants and personal fees for lectures, advisory board work and meeting attendance from AstraZeneca, grants from GlaxoSmithKline and Genentech, personal fees for advisory board work from Theravance, outside the submitted work. J. Fingleton reports grants from Health Research Council of New Zealand, during the conduct of the study; grants, personal fees for lectures and non-financial (travel) support from AstraZeneca, grants from GlaxoSmithKline and Genentech, personal fees for lectures and non-financial (travel) support from Boehringer Ingelheim, outside the submitted work.

Support statement: The study was funded through a programme grant (15/573) provided by the Health Research Council of New Zealand to the study sponsor, the Medical Research Institute of New Zealand (MRINZ). MRINZ had overall responsibility for the study conduct, monitoring, and data management. The funder had no role in the design, data collection, data analysis or interpretation, or writing of the manuscript. All authors had full access to the data analysis report, assisted in the writing of the manuscript and approved the final version. The randomised medications were purchased commercially. Funding information for this article has been deposited with the Crossref Funder Registry.

\section{References}

1 O’Byrne PM, FitzGerald JM, Bateman ED, et al. Inhaled combined budesonide-formoterol as needed in mild asthma. N Engl J Med 2018; 378: 1865-1876.

2 Bateman ED, Reddel HK, O’Byrne PM, et al. As-needed budesonide-formoterol versus maintenance budesonide in mild asthma. N Engl J Med 2018; 378: 1877-1887.

3 Beasley R, Holliday M, Reddel HK, et al. Controlled trial of budesonide-formoterol as needed for mild asthma. N Engl J Med 2019; 380: 2020-2030.

4 Hardy J, Baggott C, Fingleton J, et al. Budesonide-formoterol reliever therapy versus maintenance budesonide plus terbutaline reliever therapy in adults with mild to moderate asthma (PRACTICAL): a 52-week, open-label, multicentre, superiority, randomised controlled trial. Lancet 2019; 394: 919-928.

5 Global Initiative for Asthma (GINA). Global Strategy for Asthma Management and Prevention, 2019 revision. www.ginasthma.org/. Date last accessed: June 28, 2019.

6 Reddel HK, FitzGerald JM, Bateman ED, et al. GINA 2019: a fundamental change in asthma management: treatment of asthma with short-acting bronchodilators alone is no longer recommended for adults and adolescents. Eur Respir J 2019; 53: 1901046.

7 Partridge MR, van der Molen T, Myrseth SE, et al. Attitudes and actions of asthma patients on regular maintenance therapy: the INSPIRE study. BMC Pulm Med 2006; 6: 13.

8 Patel M, Pilcher J, Hancox RJ, et al. The use of $\beta_{2}$-agonist therapy before hospital attendance for severe asthma exacerbations: a post-hoc analysis. NPJ Prim Care Respir Med 2015; 25: 14099.

9 Reddel HK, Busse WW, Pedersen S, et al. Should recommendations about starting inhaled corticosteroid treatment for mild asthma be based on symptom frequency: a post-hoc efficacy analysis of the START study. Lancet 2017; 389: 157-166. 
10 Engelkes M, Janssens HM, de Jongste JC, et al. Medication adherence and the risk of severe asthma exacerbations: a systematic review. Eur Respir J 2015; 45: 396-407.

11 Chapman S, Dale P, Svedsater H, et al. Modelling the effect of beliefs about asthma medication and treatment intrusiveness on adherence and preference for once-daily vs. twice-daily medication. NPJ Prim Care Respir Med 2017; 27: 61

12 Ulrik CS, Backer V, Søes-Petersen U, et al. The patient's perspective: adherence or non-adherence to asthma controller therapy? J Asthma 2006; 43: 701-704.

13 Foster JM, Smith L, Bosnic-Anticevich SZ, et al. Identifying patient-specific beliefs and behaviours for conversations about adherence in asthma. Intern Med J 2012; 42: e136-e144.

14 Bender BG, Long A, Parasuraman B, et al. Factors influencing patient decisions about the use of asthma controller medication. Ann Allergy Asthma Immunol 2007; 98: 322-328.

15 Fingleton J, Hardy J, Baggott C, et al. Description of the protocol for the PRACTICAL study: a randomised controlled trial of the efficacy and safety of ICS/LABA reliever therapy in asthma. BMJ Open Respir Res 2017; 4: e000217.

16 Global Initiative for Asthma (GINA). Global Strategy for Asthma Management and Prevention, 2014 revision. www.ginasthma.org/. Date last accessed: May 6, 2019.

17 Reddel HK, Ampon RD, Sawyer SM, et al. Risks associated with managing asthma without a preventer: urgent healthcare, poor asthma control and over-the-counter reliever use in a cross-sectional population survey. BMJ Open 2017; 7: e016688.

18 Blaiss MS, Kaliner MA, Baena-Cagnani CE, et al. Barriers to asthma treatment in the United States: results from the global asthma physician and patient survey. World Allergy Organ J 2009; 2: 303-313.

19 Harris PA, Taylor R, Thielke R, et al. Research Electronic Data Capture (REDCap) - a metadata-driven methodology and workflow process for providing translational research informatics support. J Biomed Inform 2009; 42: 377-381.

20 Harris PA, Taylor R, Minor BL, et al. The REDCap consortium: building an international community of software platform partners. J Biomed Inform 2019; 95: 103208.

21 Reddel HK, Taylor DR, Bateman ED, et al. An official American Thoracic Society/European Respiratory Society statement. Asthma control and exacerbation: standardizing endpoints for clinical asthma trials and clinical practice. Am J Respir Crit Care Med 2009; 180: 59-99.

22 Leidy NK, Gutierrez B, Lampl K, et al. Can patients with asthma feel inhaler therapy working right away? Two clinical trials testing the effect of timing of assessment on patient perception. J Asthma 2009; 46: 1006-1012.

23 Murphy KR, Bender BG. Treatment of moderate to severe asthma: patient perspectives on combination inhaler therapy and implications for adherence. J Asthma Allergy 2009; 2: 63-72.

24 Caminati M, Senna G, Stefanizzi G, et al. Drop-out rate among patients treated with omalizumab for severe asthma: literature review and real-life experience. BMC Pulm Med 2016; 16: 128.

25 Nordon C, Karcher H, Groenwold RHH, et al. The "efficacy-effectiveness gap": historical background and current conceptualization. Value Health 2016; 19: 75-81. 